\title{
Social and Spatial Precursors to Innovation: The Diversity Advantage of the Creative Fringe
}

Ana Bilandžić

Dario Casadevall

Marcus Foth

Greg Hearn
Queensland University of Technology, Australia ana.bilandzic@qut.edu.au Corresponding Author

Ludwig Maximilian University of Munich, Germany d.casadevall@campus.lmu.de

Queensland University of Technology, Australia m.foth@qut.edu.au

Queensland University of Technology, Australia g.hearn@qut.edu.au

Innovation spaces and hubs are increasing in numbers internationally. Entrepreneurs and start-up founders who use these spaces and hubs are often unaware of being inside an echo chamber, i.e. a filter bubble they share with only like-minded people who have similar ideas and approaches to innovation. Digital technologies that use algorithms can aggravate these echo chambers by filtering towards improved personalised experience and preferences. Yet, social inclusion fosters diverse ideas and creativity, hence, has a positive impact on innovation. We studied the social navigation patterns of entrepreneurs and start-up founders, and their awareness and opinion about homogeneity in innovation spaces. This data informed the design of a tool to escape their echo chambers. The tool gives its users the opportunity to discover networks and innovation spaces that are at the creative fringe, that is, marginalised from mainstream spaces and hubs for creativity and innovation. Our findings show that users of innovation spaces often find themselves surrounded by like-minded

Bilandžić, A., Casadevall, D., Foth. M., Hearn. G. (2018). Social and spatial precursors to innovation: the diversity advantage of the creative fringe.. The Journal of Community Informatics, 14(1), 160-182.

Date submitted: 2018-10-01. Date accepted: 2018-10-15.

Copyright (C), 2018 (the author as stated). Licensed under the Creative Commons AttributionNonCommercial-ShareAlike 2.5. Available at: www.ci-journal.net/index.php/ciej/article/view/1455 
people. Further, our study participants welcomed the ability to identify fringe spaces in order to discover and access more diverse people and ideas. Our approach seeks to unlock the diversity advantage of the creative fringe for the purpose of creativity and innovation.

Keywords: innovation precursors; innovation hubs; echo chambers, network theory, homogeneity vs. diversity.

\section{Introduction}

Innovation spaces and hubs provide people with new environments for ideation and collaboration on their innovation endeavours. Therefore, they are often linked to the start-up and entrepreneurship scene. Although established corporate businesses may be associated with pursuing incremental innovations while start-ups are often seen as taking more risk for pursuing disruptive innovations (Freeman \& Engel, 2007), we acknowledge that innovations have a much broader base. This also includes social innovation and social entrepreneurship as well as innovative pursuits and initiatives led by those less concerned with the financial profitability of an eventual business prospect. This manifold source of different kinds of innovation might be the reason why innovation spaces have seen increased attention, support, and funding from both public and private sectors (Moriset, 2013). Further, innovation spaces are increasing in numbers across Australia and internationally (Bouncken \& Reuschl, 2016; Gandini, 2015; Kojo \& Nenonen, 2014). If they aim to target a particular sector or outcome, then their 'speciality [...] may attract certain more homogeneous individuals' (Bouncken \& Reuschl, 2016, n.p.), hence, others with different interests and backgrounds are excluded. For instance, topics around technology and digital design seem to prevail in established and government supported innovation spaces. Such spaces often bring together mostly people with a STEM background, whereas people from design, arts, humanities and social sciences risk being alienated in the 'creative fringes' (Foth, 2015; Foth, Hughes, Dezuanni \& Mallan, 2017). Additionally, natural social mechanisms and algorithms for recommendations on the internet amplify the rise of echo chambers and filter bubbles (Pariser, 2011). Consequently, innovation spaces and hubs may reinforce homophily by hosting more and more like-minded people who share the same interests and even skill sets. This counteracts the initial benefits of the internet to actually have access to the long tail, i.e. diverse products and services in the niche rather than the mainstream (Anderson, 2008).

Nevertheless, statements about homogeneity or diversity in innovation spaces contradict each other leading to confusion. For instance, some statements assert that the spaces attract people 'with certain personalities or similar (creative) jobs' (Bouncken \& Reuschl, 2016, n.p.) or who are 'largely working in the same sector' (Gandini, 2015, p. 195). Yet, others state that 'a diverse group of people who don't necessarily work for the same company, or on the same project' (DeGuzman \& Tang, 2011, p. 22) use these spaces. These contradictory quotes bring uncertainty about if, and to what extent, innovation spaces are characterised by diversity. While homogeneity might be useful to make groups gel and be productive, e.g. similar people and businesses collocate in 'precincts' or 'hotspots' (Adkins, Foth, Summerville \& Higgs, 2007), diversity is 
needed for ideation, problem solving and resilience (Foth, Forlano \& Bilandzic, 2016). Foth (2015) calls for considering the 'creative fringes' and 'skunkworks,' i.e. places where the fringes meet, in the realm of innovation. Social inclusion of diverse people and groups in innovation benefits the creative processes as well as economic outcomes (Wood \& Landry, 2007).

In this study, we aim to understand the social and spatial precursors that impact innovation in innovation spaces. Precursors can be understood as help and encouragement for better learning, networking, action and novel ideation, that is, the first steps towards mobilising people to be innovative and entrepreneurial in their thinking and actions. We introduce and analyse three examples to clarify the notion of precursors.

The 'Start-Up India; Stand-Up India' initiative under prime minister Narendra Modi provided incentives and help setting up a network for start-ups encouraging youth, women and those historically seen at the bottom of the caste hierarchy to access entrepreneurial training (PTI, 2015).

The Foundation for Young Australians (FYA) helps young people who are creative, ambitious and want to create a better future to find their passion; backs them to listen, learn, experience, and take action; and assists them in finding a community to build a network (FYA, 2018).

The State of Queensland (2017) aims with its Advancing Regional Innovation Program to harness innovation in its regions by supporting innovative communities that represent 'the diversity of Queensland's regions' and that encourage grassroot entrepreneurial activities.

Given that diversity of people is a good starting point for ideation for innovation (Callon, 1990; Granovetter, 1973) and that there is a lack of comprehension on the degree of diversity in innovation spaces, this study looks at people's awareness and opinion about their lived experience of homogeneity and diversity in these spaces. To do so, we designed and user-tested a skunkworks finder prototype, to provide our study participants with an experimental tool to escape their echo chambers. It gives our study participants the opportunity to discover networks and innovation spaces that are at the creative fringe and marginalised from mainstream spaces for innovation. Users can map innovation spaces and hubs relative to their location and interests. Finally, places unfamiliar to the users will be presented on the map.

The remainder of the article is structured into four main sections. First, we review relevant literature on innovation spaces and hubs, the diversity advantage in innovation, and the relative lack of diversity in many innovation spaces. Second, we introduce our study's methodology. Then we evaluate and discuss our findings. Finally, the conclusion summarises our main findings, suggesting managerial implications and future work. 


\section{Literature Review}

\section{Innovation Spaces}

The knowledge economy, which relies more on intellectual capabilities than on natural resources or physical inputs (Powell \& Snellman, 2004), changed the way individuals work, companies operate their business, and innovation is achieved. The web (Leadbeater, 2009) and digital technology (Castells, 2010) was thought to give the idea of remote working the opportunity to become a 'game changer' (Barthelemy, 2016, p. 246). Coworking spaces may turn into 'a harbor for entrepreneurs,' because people can push their ideas in an environment that is based on knowledge transfer and mutual learning (Bouncken \& Reuschl, 2016, n.p.). Therefore, they provide alternative innovation environments to scientific laboratories, universities, or research and development (R\&D) departments of companies. Employees or freelancers become nomads who travel with their work across the urban environment (Foth et al., 2016). Now the office can be the home, libraries, coworking spaces, maker spaces, innovation spaces and hubs, or even remote travel destinations (known as 'workations' or coworking holidays). In the remainder of this article, we refer to these coworking and innovation environments as innovation spaces. Liegl (2014) demonstrates that mobility becomes both a problem and a resource for urban nomads. He explains that the problem encompasses the restless search for the right space - a challenge also found by Rossitto Bogdan, and Severinson-Eklundh (2014), Forlano (2011), and Townsend, Forlano and Simenti (2011), whilst the restlessness has the potential to stimulate creativity.

The new genre of innovation spaces seems to be more playful, open, and transparent than conventional innovation places such as laboratories or R\&D departments (van Meel \& Vos, 2001). Because diversity drives innovation, an openness towards a hub for heterogeneity to welcome as diverse interests as possible could be understood. This gives reason to expect a diverse mix of people inhabiting these innovation spaces, e.g. with different levels of education, educational backgrounds, socio-cultural backgrounds and in terms of other diversity scales. If this is the case, situational influences of place affect innovation (Sayiner, 2015) - meaning that the environments, composed of people, culture and physical space, function as a mediator of individual creativity, and hence, impact on the space's capacity to foster innovation. Sayiner (2015) argues that the design of physical space should aim to maximise spontaneous encounters between people especially between those from different departments in an organisation. For instance, spontaneous encounters could happen at the coffee machine, in the hallway, or community events such as at happy hours on Fridays (Sayiner, 2015). Further, open office plans give more opportunities for socialising, but then smaller spaces are required for 'zoning,' for team work, or individual privacy (Sayiner, 2015). Many of these design recommendations have been implemented in innovation spaces. Besides the spatial design, previous research showed how hybrid placemaking, i.e. combining spatial, social and digital space to facilitate social interaction, can improve connected learning amongst on-site people of a casual environment (Bilandzic \& Johnson, 2013).

Users of innovation spaces share the physical assets, e.g. café, office, infrastructure, and intangible assets, e.g. information and knowledge (Bouncken \& Reuschl, 2016). A 
careful consideration of spatial, social and technological aspects for designing these spaces can nourish peer interactions, facilitate shared encounters, and connected learning (Bilandzic \& Foth, 2017). The meaning of these design aspects gain weight when users know that people come and use innovation spaces, because they want to be part of a community, too, rather than accessing the workspace itself (Garrett, Spreitzer \& Bacevice, 2017). Innovation spaces allow social interaction that can inspire people and increase idea exchange and development (Bouncken \& Reuschl, 2016) as well as knowledge exchange to get new insights that support them in their entrepreneurial or innovative endeavours (Foertsch, 2011). In a survey with 661 coworkers from 24 countries, Foertsch (2011) found that people made new acquaintances in innovation spaces that had positive impacts on their work. For instance, he found that $43 \%$ of the respondents met one to three helpful coworkers, while another $43 \%$ met four or more such acquaintances. Although people often pay a fee to access innovation spaces, the prevailing primary justification is the sense of belonging to a community (Garrett et al., 2017). This finds support in a socio-spatial analysis of innovation spaces where people perceive the spaces 'as social environments, rather than purely physical destinations' (Bilandzic \& Foth, 2017). The small communities in which they find themselves come with a warm feeling and sense of belonging (Czarniawska, 2014). Innovation spaces are becoming popular working spaces for co-creation, coworking, and collaboration, because more and more people believe that working alongside each other sparks great ideas that can lead to new entrepreneurial initiatives (DeGuzman \& Tang, 2011; Hughes, Morgan, Ireland \& Hughes, 2014). Not just private sector but also government staff reported key benefits such as cost savings on transport and child care, improved workplace flexibility, workforce participation and job satisfaction, and use of personally preferred technologies when working from an innovation space such as a coworking space (Houghton, Foth \& Hearn, 2018).

Further, the motivation to work in innovation spaces is partly driven by people's desire to be part of a community (Garrett et al., 2017), because remote, home, or teleworkers often feel isolated (Golden, Veiga \& Dino, 2008; Whittle \& Mueller, 2009). Although the home or coffee shop may be appropriated as a temporary office, people desire a sense of community that fills a social void and gives them a collective identity, a sense of ownership, and a feeling of genuine friendship (Garrett et al., 2017). Bilandzic and Foth (2013) gained deeper understanding of the motivation of people coming to coworking spaces and their uses of these spaces, which we previously put under the umbrella word of innovation spaces. They classify:

- Utiliser who benefits from the free access to technological infrastructure that would otherwise be too expensive to buy;

- Socialiser who coworks with individuals and groups, and;

- Learner who acquires knowledge at workshops, exhibitions, presentations, and other events.

This again provides insights about people's motivation to visit innovation spaces. Besides the free access to technology, they aim for informal learning and socialising (Bilandzic \& Foth, 2013). Although innovation spaces thrive in today's knowledge- 
based economy that relies on creativity, communication, collaboration, problem solving, and critical thinking skills (Bilandzic \& Foth, 2013; de Laart \& Dawson, 2017; Kojo \& Nenonen, 2014), they might represent only temporary clusters for the people using them, because less than $60 \%$ of them consider themselves as being loyal to one space (Foertsch, 2011).

This may explain why people in innovation spaces are sometimes described as (digital) nomads (Czarniawska, 2014; Liegl, 2014; Rossitto et al., 2014). Nomadism comes with a notion of temporary rest and moving along. Multiple studies show issues that occur during people's stay in innovation spaces (Bilandzic \& Foth, 2013; Czarniawska, 2014; Forlano, 2011; Gregg, 2011; Houghton et al., 2018). Yet, with a nomadic working lifestyle, some challenges might be present even before people enter innovation spaces. People need to find an innovation space first. Forlano (2011), Liegl (2014), and Rossitto et al. (2014) found that the search for a suitable innovation space is a burden for many people.

\section{Diversity Advantage in Innovation}

The role of people in innovation is clear as they are the creators of innovation (Gladwell, 2000). Developing new ideas for innovation is a process that builds connections between existing knowledge following a logic of discovery or innovation (Polanyi, 1962). However, a 'logical gap' can lead to a lack in logical reasoning (Polanyi, 1962). In this case a scientist's 'illumination,' that is, a creative imagination driven by feasible clues and intuition leads to the creation of a new concept (Polanyi, 1966). Rust (2004, p. 78), who is inspired by Polanyi's argument, concludes that 'the ability of designers to imagine new scenarios' and create environments with experimental artefacts that allow people to experience these scenarios, can help scientists to 'identify ideas that merit investigation.' Following these arguments, ideas for innovation come from logical reasoning or from a creative imagination that leads to ideas for discovery and innovation.

The innovation process in a commercial context is often broken down into several steps. For instance, Hauschildt and Salomo (2011) suggest a seven-step model that starts with ideation, followed by discovery/observation, research, invention, development, and market launch, and ends with market penetration. Even though this model does not suit all kinds of innovation, e.g. social, civic, or ecological innovations, we use it here to exemplify the different steps that require a set of different tasks for accomplishment. Researchers have found that people have different personality characteristics (Callon, 1990; O’Connor, 2006; O'Connor \& McDermott, 2004; Roberts \& Fusfeld, 1982) and motivations (Battistella \& Nonino, 2013) varying amongst these steps, hence, the required activities in the innovation process. As a consequence, some people may perform one step better than another. For instance, someone who is comfortable with abstract work and performs well in problem solving is good in seeking breakthroughs and generating new ideas (Roberts \& Fusfeld, 1982). In contrast, a person with strong interest in applications, is entrepreneurial and adept at selling the idea to get funding (Roberts \& Fusfeld, 1982). In summary, this means that the different steps along the innovation process are complementary and require different skills, tasks and activities 
that are more or less suitable to particular personal characteristics and motivations. Having this in mind and knowing that intrinsically motivated work leads to higher personal happiness (Csikszentmihalyi, 2002) and positively influences the innovation process (Koudelkova \& Milichovsky, 2015), it becomes apparent that a diversity of people enriches the innovation process as a whole. Consequently, people with diverse skill sets and interests in innovation spaces might positively influence each other's work, as well as contribute to the sense of community in the innovation space.

We look at social interaction and network theory to better understand why diversity promises a positive influence on innovation. Individuals who work by themselves and come up with a great idea are an exception (Johnson, 2010). Whereas individuals with contacts to different groups span structural holes between these groups, and detect and develop opportunities to generate valuable new ideas (Burt, 2005). This corresponds to the idea of people at the fringes of one's social network (Granovetter, 1973). These people have ties to at least two social networks that allow them to gain insights from both. Therefore they find themselves in a situation that allows them to connect the structural holes from both networks and potentially create new ideas. Johnson (2010, p. 22) argues, 'Good ideas may not want to be free, but they do want to connect, fuse, recombine [...] by crossing conceptual borders.' However, sometimes big breakthroughs happen when technology is ready, e.g. after inventors conducted research and experiments for a long time in laboratories, only then do designers come in and start understanding the needs of users (Norman, 2010). This again shows the need for diversity in innovation as two professions are involved in making a technological breakthrough a success. Even in scientific laboratories, innovative thinking occurs when researchers have their weekly meetings (Dunbar, 1997). Social networks can be inspiring, because mostly they deal with less serious issues and therefore give the mind the opportunity to spin freely as aroused by the 'nothingness' (Traitler, Coleman \& Hofmann, 2015, p. 199). These insights show the value of social interaction and the role of diversity with regards to innovation.

As we know that diversity can be an advantage for creativity and innovation, we looked at examples from industry to understand how diversity can be built in organisations. Broadly speaking, we can see a change in the innovation process since Chesbrough introduced the open innovation paradigm in 2003 (Chesbrough, 2003). Since then companies exchange intellectual property throughout the innovation process with other companies from the same or a different industry. They also value and source ideas from their customers and employees (Piller, 2011). For instance, Google introduced a 20\% policy that is inspired by 3M's 15\% policy (Girard, 2009). It allows its employees to use $20 \%$ of their work time, i.e. one day per week, to follow individual interests. This policy led to new innovations such as Google News. Google's Senior Vice President of People Operations Laszlo Bock said that at Google, 'We try to have as many channels for expression as we can, recognizing that different people, and different ideas, will percolate up in different ways' (He, 2013). This shows Google's openness, appreciation, and encouragement to diversity of people and approaches for innovation. The company King, which is in the digital game industry, which developed games such as Candy Crush, actively pursues building a diverse team. Its manager for employer brand, diversity, and culture Natalie Mellin says that for recruitment King pursues diversity 
considering 'areas that are [...] discriminated against in the workplace' (Batchelor, 2017). To do so, King looks at its statistics such as how many employees belong to the LGBTIQ+ community, have kids, or look after their elders, the gender split, and nationalities (Amelie, 2017).

Efforts towards creating diverse teams are also undertaken in innovation spaces. Rei Inamoto, who was the chief creative officer at AKQA, said at South by Southwest that 'a Hipster, a Hacker, and a Hustler' build an efficient entrepreneurial team (Ellwood, 2012). In this context, the hipster is the designer, the hacker is the technology expert who codes, and the hustler is the business expert who sells the product. Following this credo, the Meetup group 'Hipsters, Hackers \& Hustlers' gathers for those interested in London's startup scene. Similarly, the Google for Entrepreneurs backed Startup Weekend series (startupweekend.org) comprises teams of hipsters, hackers and hustlers developing an idea into a business within 54 hours. Although this constellation brings three backgrounds together and might appear diverse, those teams usually focus on technology in their entrepreneurial and innovative endeavours, maybe because they believe that problems can be solved with some sort of (temporarily lasting) technology. Instead they could try to understand the problem at its roots from a humanities and social science perspective, and help people to develop skills to innovate with value and substance to remedy the cause rather than easing the pain.

\section{Lack of Diversity in Innovation Spaces}

Studies on innovation spaces reveal the occupations of people who come to these spaces. Most often they are freelancers, remote workers, self-employed, entrepreneurs, consultants, contractors, or own or are part of a small start-up (Gandini, 2015; Garrett et al., 2017, p. 826; Spinuzzi, 2012). Foertsch's (2011) survey shows that 54\% are freelancers, $20 \%$ are permanent employees, and almost $20 \%$ are entrepreneurs who employ others. Foertsch (2011) outlines that the majority of people - without providing statistics - work in the creative industries and new media where one in nine are graphic or web designers and the same number are consultants. The reason may lie in the evolution of the creative industries 'from a sector-specific mapping to economy-wide focus on creative inputs as generative of change and innovation' (Cunningham, 2011, p. 59). Further, Foertsch (2011) reports that others work in public relations and marketing, or as journalists, writers, architects, and artists. Although the jobs within the creative industries can be different, innovation spaces might be homogeneous in a sense that only mobile workers from the creative industries who can use their laptop for work come together. Therefore, we argue that many mainstream innovation spaces have a focus on technology and digital design, leaving out people from other design areas, arts, humanities and social sciences who are pushed to become the 'creative fringe' (Foth, 2015; Foth et al., 2017).

Australia's Department of Industry, Innovation and Science (Department of Industry, Innovation \& Science, n.d.-a) defines innovation as 'the implementation of a new or significantly improved product or process, a new marketing method, or a new organisational method in business practices, workplace organisation or external relations.' It shows that the equivalent of $3.11 \%$ of Australia's gross domestic product 
was spent on R\&D in 2015. The department measures innovation activities through R\&D expenditure, trademark and patent application, and new business creation (Department of Industry, Innovation \& Science, n.d.-b). The Australian Innovation System annual series reports on the impact innovation has on business, industry, and national performance (Commonwealth of Australia, 2018). Additionally, the Australian Industry Report focuses on economic factors affecting industries (Commonwealth of Australia, 2018). These insights might give a clue why government funded innovation spaces often only focus on technology-driven commercial outcomes, while the government should consider the rising creative economy, hence, the education and learning of non-technical skills (Cunningham, 2018). Algorithms in digital technologies might put the creative fringes in danger to fall off the innovation radar. Innovation measurements used by the government might be exclusive of any social and ecological innovation outputs, as no data on these innovation types are provided. Ignoring these innovation types and non-monetary oriented methods to measure innovation ignores social and ecological issues. Further, they put society in danger of falling prey to neoliberal capitalist agendas, ignoring social problems such as hunger, homelessness, and climate change (Monbiot, 2016).

Previously, we showed that diversity has a positive effect on innovation, hence, inclusion of everyone is a meaningful stance in regard to innovation and might bring benefits to innovation spaces. However, creating diversity might be difficult, because people tend to stay within the comfortable centre of gravity of their social network (Granovetter, 1973). By using software-sorted geographies and algorithmic curation, people increasingly risk to fall into polarisation when using digital technology to search for new spaces (Foth, Mitchell \& Estrada-Grajales, 2018). This is due to algorithmic filters that usually sort and prioritise search results according to homophily and sameness. These algorithms work counter to the argument that innovation thrives on diversity if they lead the same people to meet in the same spaces all the time (Foth, 2015).

Bouncken and Reuschl (2016) suggest future research on innovation spaces to focus on analysing precursors in regard of entrepreneurship and innovation and on investigating the influence of precursors such as availability of diverse skills on entrepreneurial success, time to market, or new product development that are the outcome of selfefficacy. With that in mind we aim to understand the spatial precursors that set the ground for innovation in innovation spaces that allow us to learn about people's awareness and opinion about homogeneity or diversity in innovation spaces and provide them a tool to escape their echo chambers.

\section{Methodology}

This study is part of a larger study that involved the development, verification and validation through user testing of the prototype skunkworks finder that aims to help people escape their filter bubble and discover new innovation spaces in their city. This study looks deeper into the findings regarding (a) participants' methods of social navigation and searching for innovation spaces and their awareness of homogeneity or diversity in them, and; (b) participants' willingness to use, and their perceived need for, 
a tool that might help them to escape their echo chambers. For the matter of simplicity, we will provide an explanation of the developed prototype rather than detailed technical features and operations, which are reported elsewhere. This is followed by data collection and analysis methods.

The skunkworks finder is a tool assisting users to expand personalised social navigation and discover new and different innovation spaces where serendipitous new acquaintances, idea exchange, and innovative thinking may occur. The larger study is following an iterative design strategy that complies with the design inclusive research paradigm (Bruseberg \& McDonagh-Philp, 2001; Imre, 2007). It consists of (a) a prestudy phase of hypothesis and concept development through desktop research and the design phase of the prototype, and; (b) a post-study phase for prototype testing, examination and evaluation in one-on-one user tests and interviews.

For the desktop research, we reviewed Granovetter's (1973) social network theory and followed his argument of the strength of weak social ties. Weak ties span structural holes between networks and bring new information into close network groups (Barabási, 2014; Granovetter, 1973). We were inspired by the idea of the strength of weak social ties and sought to translate it into accessing new (online) information, because it suits the basic structure of the internet. The long tail which provides access to more distinct products and services is the main strength of the internet (Anderson, 2008). Therefore, diversity should be easily achievable, if algorithms would not counteract and work towards like-mindedness and personalisation. Academic researchers have been successful in seeing the potential of social network analysis. For instance, they were able to gather user data from Twitter to retrieve information about lesser known countries to increase interest and insights into political and cultural viewpoints (Mejova, Borge-Holthoefer \& Weber, 2015). Further, they showed that more than half of their study participants were interested in the new information. Two other studies used an online tool to facilitate interdisciplinary research in their university (Valdez, Özdemir, Yazdi, Schaar \& Ziefle, 2015; Valdez, Schaar, Ziefle \& Holzinger, 2014). The tool visualised researchers and their papers on a node graph and connected them to peers if they collaborated on publications. Specific data for the tool was accessed from the integrated library system from the respective university.

For our prototype, we followed the same idea of retrieving existing data and used the weak ties to access new types of information. Our network-based recommendation tool follows the concept of LinkedIn search requests that can be sorted by degrees of separation, i.e. the number of ties that separate two distinct individuals. For instance, two users with one mutual contact are separated by one degree. We appropriated this concept from a people context to an innovation space context. This required a suitable dataset with available location-based data and specific themes with a network structure. We found that websites that map innovation spaces lack the connectivity approach to build a network around them and did not include thematic information to indicate diversity of disciplines.

For our study, we chose Meetup (www.meetup.com), because it aims to bring together people who are interested in creative processes and who want to work collaboratively. It 
holds a vast pool of differently themed groups and provides data about location. If users join a specific group, they can attend the group's meetings, meet new people, and pursue creative activities. Group organisers hold meetings at places in open facilities, e.g. cafés, libraries, university campuses, innovation spaces, or public parks. They also choose tags to characterise their groups' topics, interests, and disciplines.

Our choice of Meetup as a platform to retrieve data of innovation spaces and base our prototype for a social network of these spaces on that data comes with limitations. First, Meetup is a platform that allows its members to join groups that meet up at innovation spaces, co-working spaces, cafés or other places that accommodate people from a wide range of professions. As such it may miss co-working spaces specialised for entrepreneurs in one field, e.g. arts or technology-driven enthusiasts. Second, we appropriated the social network theory to build a prototype for a network of innovation spaces that Meetup members choose and visit. In this regard, we are missing spaces that are not frequented by any Meetup group. For instance, studios and creative practices that are the creative workspaces for artists, designers, and craftspeople, but might also be their homes, too, thus not publicly listed on the Meetup website.

Our prototype expands the curatorial repertoire of algorithmic filters by extending personalisation and building bridges to new network clusters. This is visualised on a map. The emphasis is on extending personalisation rather than displaying new information randomly chosen from the large pool of information that is provided on the internet. With the prototype we want to make people aware of their own echo chamber and give them an opportunity to discover new places for their creative and innovative work.

\section{Conceptualisation of the Prototype}

The prototype allows users to select one or more of six keyword groups that were previously retrieved as group tags: writing; art \& culture; career \& business; hobbies \& crafts; photo, audio \& video; and tech. Markers illustrate related places on a map. Additionally, connected places are displayed. The markers are colour coded to indicate the degree of separation to the places related to the initial keywords. Figure 1 is a screenshot of the prototype that shows the markers illustrating places associated with the keyword 'hobbies \& crafts' and three degrees of separation. 


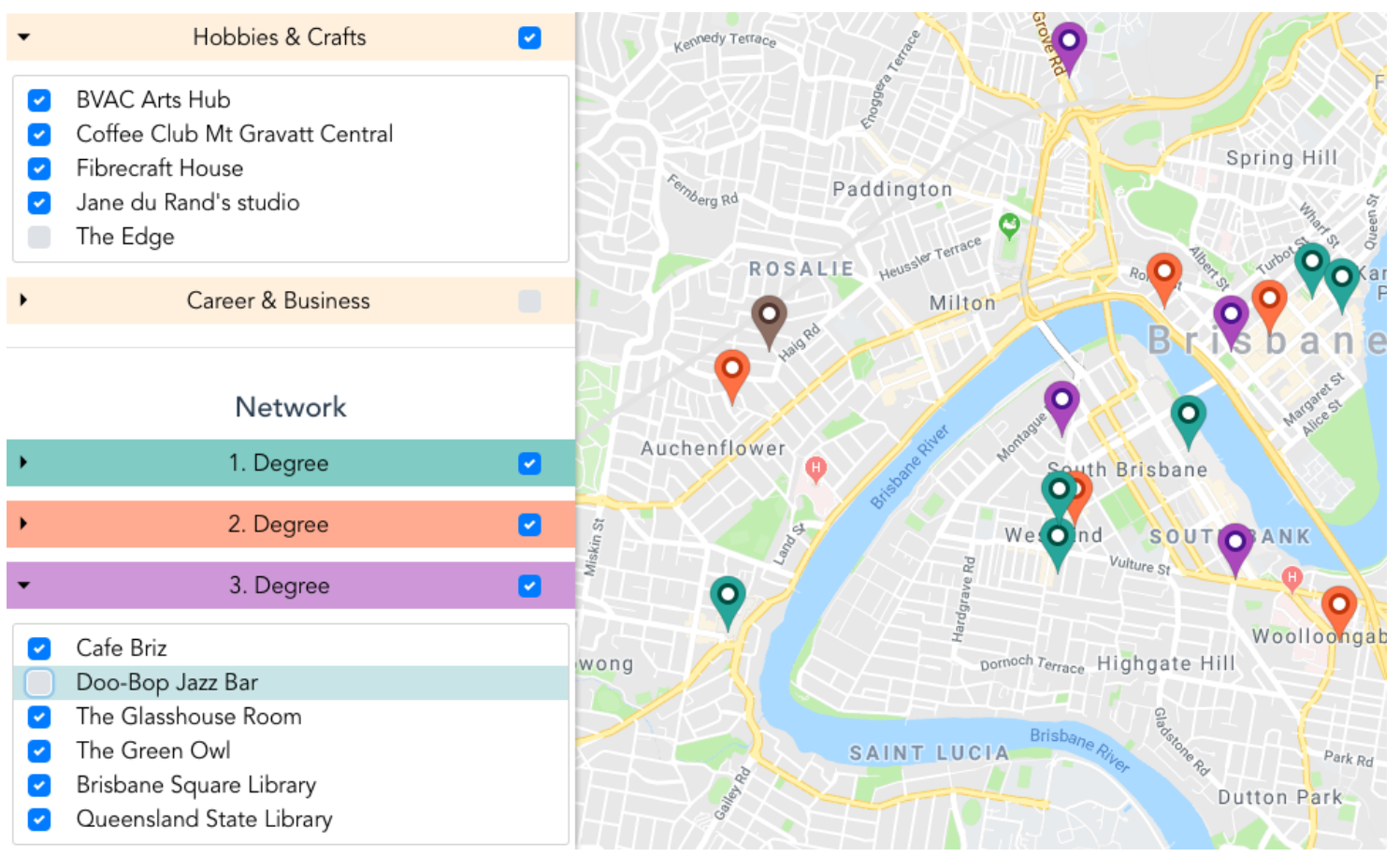

Figure 1: Map-view of Skunkworks Finder with the regular filters visible

Users get additional information about place names, address, opening hours and general topic if they click on a marker. Further, they can find out more about the connection to the other innovation spaces through two types of filters: regular and advanced. The regular filter allows the user to hide specific degrees of separation from the map.

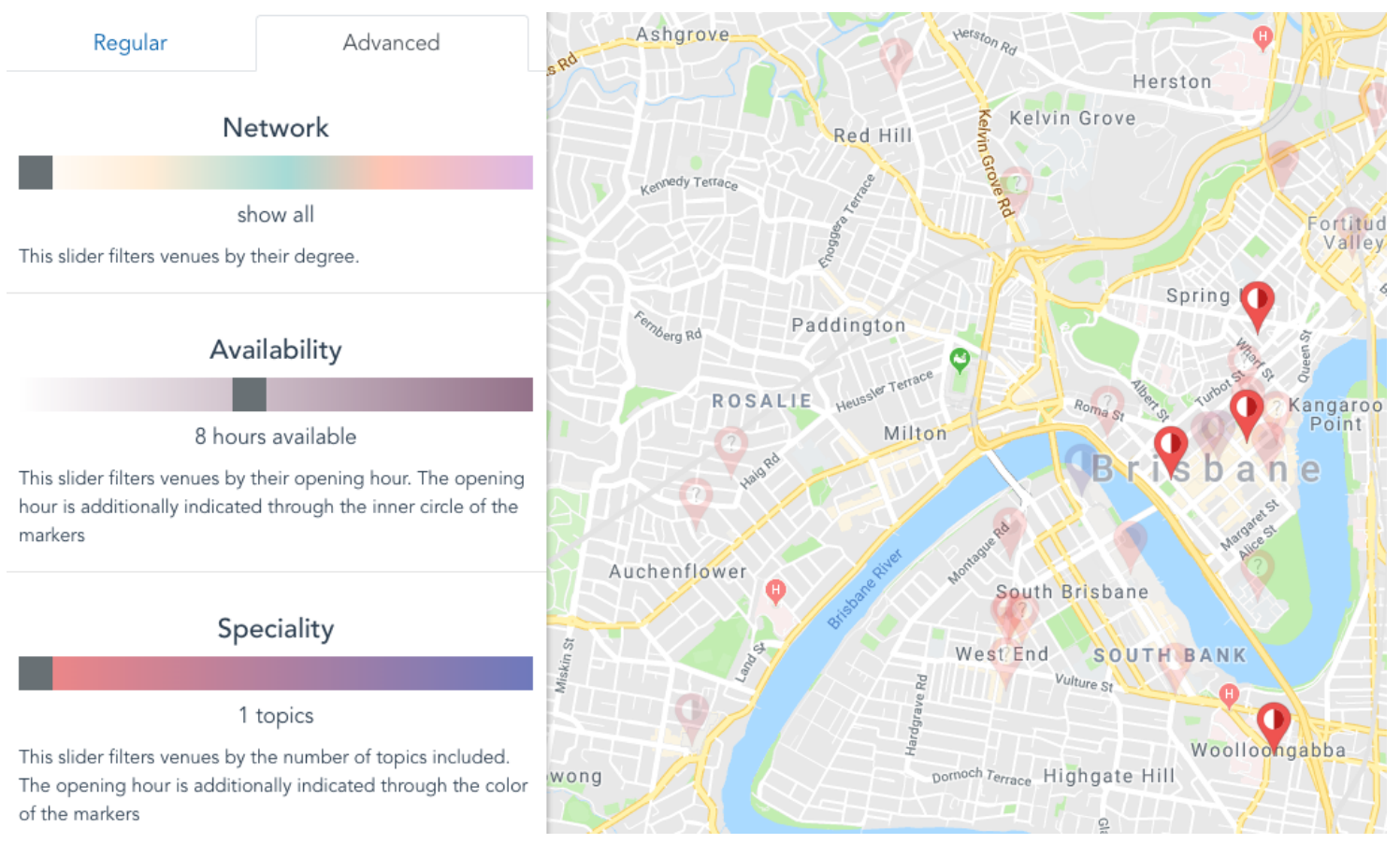

Figure 2: Map-view of Skunkworks Finder with the advanced filters visible

Figure 2 illustrates the three advanced filters for degree of separation, availability, or speciality of the innovation space. The degree filter illustrates only the innovation 
spaces of a specific degree and fades out all the remaining spaces. The availability filter corresponds with the opening hours of the innovation spaces, and the speciality filter relates to the number of thematically different meetup events being held at any one space. A space that only caters for one theme is considered specialised (e.g., a hacker space optimised for physical computing activities such as soldering), whereas a space that can cater for many themes (such as a café) is considered generic (Foth et al., 2016).

\section{Data retrieval}

This section gives a brief overview of the logic that we followed to translate member participation in different groups to form a structure for the meetup network. After a user selects a keyword, an algorithm scans Meetup groups in and around a set locale for the specific keyword via the meetup-API. Our prototype is narrowed down to the city of Brisbane and a $25 \mathrm{~km}$ radius from the CBD. We then collect the locations of past and scheduled meetings of the groups retrieved from this query. In order to avoid complexity in the experimental map visualisation, only groups that met in the last two years and more than three times at the same location within the last ten meetings are saved. Then, group members and what other Meetup groups they attend are analysed we consider this the second degree of separation in this place-based context. These new groups are then analysed for validity, i.e. to fit at least one of the six keyword groups. If the validation is successful, the examination of the meetings and members starts again.

\section{User Study}

Besides the goals of this study, the larger study also comprised a user study to validate the usability and utility of our prototype. Feedback received informed further incremental refinement of the user interface.

For our data collection, we recruited 12 participants who attend or are affiliated with innovation spaces. Their use of innovation spaces includes work or study purposes, networking events, participating in hackathons, and visits simply out of curiosity. While all our participants use Google Maps regularly, i.e. at least once a day, only half of them had heard of Meetup before. Data was collected through semi-structured interviews lasting about 45 minutes each. The interview was divided into three parts of about 15 minutes each. The first part gathered information about the usual participation purpose, use and experience in innovation spaces and the strategies they employ to discover spaces that are potentially new to them. We encouraged them to explain how and why they look for specific innovation spaces and share their personal views on a perceived benefit from (or lack of) socio-cultural or disciplinary diversity in innovation spaces and their ideas about ways to rectify this issue. The second and third parts focused on the prototype testing and explored utility and usability aspects of the prototype respectively. We recorded the interviews for follow-up transcription and thematic data analysis. 


\section{Discussion}

This study aims to shed light onto the social and spatial precursors that impact innovation in innovation spaces. We followed the argument that diversity offers a nurturing foundation for creativity and innovation and that algorithms employed in digital tools risk homogeneity, which counteracts the diversity needed for creativity and innovation. While established and government funded innovation spaces are focusing on opportunities to commercialise digital technology, people from the creative fringe often fall off the innovation radar. For this study, we looked deeper into the findings for (a) participants' methods of social navigation and searching for innovation spaces and their awareness of homogeneity or diversity in them, and; (b) participants' willingness to use and need for a tool that might help them to escape their echo chambers.

\section{The Challenge of Homogeneity in Searching for Innovation Spaces}

At the beginning of the interview, we asked study participants for a reason why they come to innovation spaces. Most of them use innovation spaces, because it enables a change of scenery whilst keeping a work atmosphere in which they are surrounded by other people in the same situation. Others appreciate the networking opportunities that open the door to connect to the start-up scene, or to learn about new ways of being creative. Our findings affirm outcomes of the previous study that created user personas of coworking spaces, i.e. utiliser, socialiser, and learner (Bilandzic \& Foth, 2013).

Methods the study participants use to find respective innovation spaces were not surprising. Either they use Google search or Facebook recommendations, or more commonly, they rely on their friends' recommendations following a word-of-mouth strategy. Both are strategies for social navigation (Dourish \& Chalmers, 1994) that give people reason to choose and visit a specific site in their environment. Both unmediated navigation (Bilandzic \& Foth, 2009) through friends as well as mediated navigation (Bilandzic, Foth \& De Luca, 2008) through devices using algorithms such as Google, support our assumption that innovation spaces are at risk of homogeneity by attracting like-minded people. This is due to recommendations made by close social networks or through algorithmic filters that are optimised for personal preferences, hence, encapsulating people within an echo chamber. All of our participants confirmed having experienced homogeneity as a result - however, this is often initially perceived as comfortable, convenient, and human nature. One participant framed it as 'Google is sorting people.' The algorithmic curation behind the scenes of social media can lead to drastic behaviour, such as that by one participant: 'Sometimes I am using another computer just to prevent ending up in a filter bubble.' Nevertheless, our participants had difficulties thinking of methods other than asking friends or following the recommendations by Google and Facebook to search for and find innovation spaces.

Several participants confirmed being in an echo chamber. One participant takes the opportunity to actively look for innovation spaces where she can find herself surrounded with people other than her peers in order to escape her perceived echo chamber. She is a doctoral student and in her opinion universities tend to be too closed off to industry. Her goal is to build connections to 'the outside world' and meet industry 
practitioners. Although she is aware of being potentially caught in a filter bubble, it seems that it takes her a bit of effort to find new spaces. Similarly, another participant has intentions to work from an environment that hosts people with diverse backgrounds. He told us, 'I have a huge interest not getting tied into one specialised group. That is what I experience right now. You start hanging out with tech people, like-minded people, and you start narrowing your focus and mind.' His enthusiasm and openness towards diversity is great, however, he confirms our assumption that the highly visible innovation spaces in the mainstream tend to be technocentric. Another participant shared his experience at a hackathon with us: "The event was a bit like "too many chiefs, not enough Indians." We had lots of people of one particular skill but no one that could actually execute on the greater plan. Tons of people were confident public speakers, but there was no one that could actually execute on the strategies that were suggested to us. It absolutely changed the whole process and outcome of the hackathon.' This statement shows his frustration with the perceived homogeneity when he attended an innovation space to participate in a hackathon. The homogeneity was so dominant that it caused difficulties in executing a proper work process and developing a competitive outcome.

On the contrary we wanted to assess statements that show participants' appreciation of working in a homogeneous group. Two participants mentioned effectiveness and efficiency of a well-attuned homogeneous group. Nevertheless, this was the case only when it came to non-creative work. It confirms that diversity positively impacts creativity and ideation especially at the early stages of the innovation process (Callon, 1990; Granovetter, 1973).

\section{Need for Ways to Discover Diversity}

After we learnt about our participants' social navigation strategies to find innovation spaces and their awareness of homogeneity in innovation spaces, we showed them, and let them familiarise themselves with, the Skunkworks Finder prototype. We received positive feedback about the idea to provide people with an opportunity to escape their filter bubble and find innovation spaces that are yet unknown to them. One participant praised our network approach to find new spaces for innovation: 'This is a great idea, because this is an easy way to broaden your network. It presents a whole extra set of possibilities, which is vital sort of stuff in terms of creativity.' Participants felt that the tool can be useful to discover innovation spaces that are unknown to them and eventually support mixing up the innovation community. They agreed that a group of people with diverse skill sets favours the ideation and creativity process. Three of our twelve participants particularly seek diverse innovation spaces. One of them stated: 'Different disciplines are very important to me. The way our group talks about what we want to do is very different and very unique to the discipline. Within this group you need to be very precise talking about something, which makes ideas and the process clear for everybody.' Even though a homogeneous group helps our participant in his working endeavours, he shows interest and curiosity in disciplines that will challenge and broaden his horizon. 
All our participants showed appreciation for the Skunkworks Finder as a tool for social navigation to escape their filter bubbles and discover new innovation spaces. However, we also found some constraints that our tool could not solve (yet). An innovation space manager pointed out the role of space and time to create a suitable base for interdisciplinary work. From her experience people in innovation spaces trust those who they see in the same place on a regular basis even if they do not engage in conversations. This refers to the notion of a familiar stranger (Milgram, 1992; Paulos \& Goodman, 2004). The participant's argument is that an online tool might not be suitable to animate people to engage in different groups, as it takes courage and a certain consistency of an individual to do so: 'You need to find a common language in diverse teams and get to know each other better. You need to invest time, in order for different people to connect and trust each other. Trust is very important. People need to have the time and be open to do that. This is not always the case.' This is confirmed by other participants who address a change in efficiency at the early stages of work or collaboration when the group is still forming. The following statement describes the work in the early stages of a new group: 'Our group is very broad with different disciplines. Just hearing different ideas and their take to problems is very interesting and helpful for the process. However, it takes time to get used to each other and learn to work together.' Finding the right balance of working in more homogeneous or diverse groups is challenging. Yet, following Granovetter (1973) and Callon (1990), groups of people with diverse skill sets or different backgrounds positively add to the creative process. Therefore, if an innovator is looking for creative ideation, designing for a more inclusive, open, and permeable environment might be beneficial. In contrast, homogeneous groups might be more efficient when it comes to getting work done (Polanyi, 1966; Rust, 2004).

Although all participants gave us positive feedback on the Skunkworks Finder and its functionalities, some participants doubt to what extent it can help anyone to discover diversity. They believe that the target group is either too narrow or the prototype does not appeal to every type of person. For instance, two participants believe that the target group is narrow, because in their opinion only people who already are interested in innovation spaces would use this tool. These are often people with an affinity for technology, which in turn risks introducing a bias in the audience. Another participant shared his concern about the tool's appeal: 'In my opinion the concept needs to be displayed differently. It is quite logical but that would not necessarily speak to an artist. There needs to be some kind of wonder that would appeal to other types of people. It needs to be radical, otherwise only logical people would use this program and that would go a bit against the original idea.' Some participants mentioned that they would be eager to use the functionalities of the Skunkworks Finder if they are implemented in an online tool that they use regularly, e.g. Google maps. We appreciate the benefits of this suggestion. If the functionalities could be accessed through Google maps, the number of potential users would increase significantly. Many more people would get an almost effortless chance to serendipitously discover new innovation spaces. This suggestion also points towards the need for better transparency and control over algorithmic filters and recommendations, so users can influence search and filter 
parameters to suit their needs rather than them being optimised for like-mindedness by default (Dourish, 2016; Foth et al., 2018).

Finally, we summarise our study's key findings regarding the two themes of homogeneity and diversity in innovation spaces and compare them to the status quo and activity in Table 1.

Table 1: Key findings regarding homogeneity and diversity in innovation spaces

\begin{tabular}{|c|c|c|}
\hline $\begin{array}{c}\text { Status } \\
\text { Quo }\end{array}$ & $\begin{array}{c}\text { Users often find themselves } \\
\text { surrounded by like-minded } \\
\text { people. }\end{array}$ & $\begin{array}{c}\text { Study participants welcome the idea of a } \\
\text { tool that assists them in discovering more } \\
\text { diverse innovation spaces. }\end{array}$ \\
\hline $\begin{array}{c}\text { Activi } \\
\text { ty }\end{array}$ & $\begin{array}{c}\text { Homogeneous groups are } \\
\text { welcomed and efficient when } \\
\text { tasks are not related to } \\
\text { creative thinking. }\end{array}$ & $\begin{array}{c}\text { Groups of people with diverse } \\
\text { experiences and skill sets are appreciated } \\
\text { when the work task requires creativity } \\
\text { and ideation. }\end{array}$ \\
\hline
\end{tabular}

\section{Conclusion}

This study is part of a larger study that involved the development, verification and validation of the Skunkworks Finder that aims to help people escape their filter bubble and discover a diversity of innovation spaces. In this article we looked more deeply into the findings regarding (a) our participants' methods for social navigation to find innovation spaces and their awareness of homogeneity in them, and; (b) their willingness to use and their need for a Skunkworks Finder to help them escape their echo chambers.

We collected data through semi-structured interviews for a user study of the Skunkworks Finder, and we used thematic data analysis for evaluation. Our findings show that users of innovation spaces often find themselves surrounded by like-minded people. This may even happen when they actively try to escape their filter bubble. We found that our participants appreciate groups of people with diverse experiences and skill sets when the work task requires creativity and ideation. However, they acknowledged the efficiency of homogeneous groups when tasks are not related to creative thinking. Further, our study participants welcomed the idea of a tool that assists them in discovering more diverse innovation spaces. Nevertheless, they would prefer to use it as an embedded plug-in for a familiar online service rather than a stand-alone tool.

Our prototype found appreciation for making visible innovation spaces that are at the creative fringe. Our qualitative study was informed by social network and social navigation theories in order to discover (and potentially design) for more diversity in innovation spaces, because diversity has positive impacts on ideation and creativity at the early stages of innovation (Callon, 1990; Granovetter, 1973). Future studies may 
improve on the range of features we tested with our prototype tool, as well as explore the right timing and balance to unlock the diversity advantage as part of an innovation strategy (Wood \& Landry, 2007). Future studies could also expand the source of data retrieval. Retrieving data for social networks of innovation spaces from another platform, e.g. Facebook or Eventbrite, may allow us to discover spaces that were not on the radar in this study due to the limitations discussed in the methodology section. Additionally, it would be useful to examine different genres of innovation and innovative pursuit separately and more in-depth, e.g., social innovation and social entrepreneurship and their specific social and spatial precursors.

Our study gives rise to many possibilities to extend this work in new directions, such as an exploration of different urban planning approaches to fostering innovation in cities and precincts (Zuckerman, 2011; Yigitcanlar \& Bulu, 2018), and - similar to privacy settings - the need for and design of control settings to increase transparency and influence search parameters in algorithmic filters. 


\section{References}

Adkins, B. A., Foth, M., Summerville, J. A., \& Higgs, P. L. (2007). Ecologies of Innovation: Symbolic Aspects of Cross-Organizational Linkages in the Design Sector in an Australian Inner-City Area. American Behavioral Scientist, 50(7), 922-934. https:// doi.org/10.1177/0002764206298317

Amelie, M. (2017, May 26). What Google and King does to achieve more diversity. Retrieved from https://planet.telenor.com/2017/05/26/what-google-and-king-does-to-achievemore-diversity/

Anderson, C. (2008). The long tail. New York: Hachette.

Barabási, A.-L. (2014). Linked. New York: Basic Books.

Barthelemy, M. (2016). Toward a new science of cities. In The structure and dynamics of cities: Urban data analysis and theoretical modeling (pp. 242-247). Cambridge: Cambridge University Press.

Batchelor, J. (2017, January 30). King on diversity: 'No company will succeed on its own here.' Retrieved from https://www.gamesindustry.biz/articles/2017-01-30-king-on-diversityno-company-will-succeed-on-its-own-here-we-need-to-show-role-models-together

Battistella, C., \& Nonino, F. (2013). Exploring the impact of motivations on the attraction of innovation roles in open innovation web-based platforms. Production Planning \& Control, 24(2-3), 226-245.

Bilandzic, M., \& Foth, M. (2009). Social navigation and local folksonomies: Technical and design considerations for a mobile information system. In S. Hatzipanagos \& S. Warburton (Eds.), Handbook of Research on Social Software and Developing Community Ontologies (pp. 52-66). Hershey: IGI Global.

Bilandzic, M., \& Foth, M. (2013). Libraries as Coworking Spaces: Understanding User Motivations and Perceived Barriers to Social Learning. Library Hi Tech, 31(2), 254273. doi: $10.1108 / 07378831311329040$

Bilandzic, M., \& Foth, M. (2017). Designing hubs for connected learning: social, spatial and technological insights from Coworking, Hackerspaces and Meetup groups. In L. Carvalho, P. Goodyear, \& M. de Laat (Eds.), Place-Based Spaces for Networked Learning. Abingdon: Routledge.

Bilandzic, M., Foth, M., \& De Luca, A. (2008). CityFlocks: designing social navigation for urban mobile information systems. In Proceeding DIS '08 Proceedings of the 7th ACM Conference on Designing Interactive Systems (pp. 174-183). New York: ACM. doi: $10.1145 / 1394445.1394464$

Bilandzic, M., \& Johnson, D. (2013). Hybrid placemaking in the library: designing digital technology to enhance users' on-site experience. The Australian Library Journal, 62(4), 258-271. doi: 10.1080/00049670.2013.845073

Bouncken, R. B., \& Reuschl, A. J. (2016). Coworking-spaces: how a phenomenon of the sharing economy builds a novel trend for the workplace and for entrepreneurship. Review of Managerial Science, 12(1), 1-18. doi: 10.1007/s11846-016-0215-y

Bruseberg, A., \& McDonagh-Philp, D. (2001). New product development by eliciting user experience and aspirations. International Journal of Human-Computer Studies, 55(4), $435-452$.

Burt, R. S. (2005). Brokerage and closure. New York: Oxford University Press. 
Callon, M. (1990). Techno-economic networks and irreversibility. The Sociological Review, $38(1), 132-161$.

Castells, M. (2010). The Rise of the Network Society (Vol. 2). West Sussex: Wiley Blackwell.

Chesbrough, H. W. (2003). Open innovation: The new imperative for creating and profiting from technology. Boston: Harvard Business School Press.

Commonwealth of Australia. (2018). Startups and entrepreneurs. Retrieved from https:// www.innovation.gov.au/audience/startups-and-entrepreneurs

Csikszentmihalyi, M. (2002). Flow: The classic work on how to achieve happiness (Vol. 2). London: Rider.

Cunningham, S. (2018, March 22). An exploding creative economy shows innovation policy shouldn't focus only on STEM. The Conversation. Retrieved from http:// theconversation.com/an-exploding-creative-economy-shows-innovation-policyshouldnt-focus-only-on-stem-93732

Cunningham, S. D. (2011). Creative industries, its critics, and some answers. Ekonomiaz, 78(3), $47-60$.

Czarniawska, B. (2014). Nomadic Work as Life-Story Plot. Computer Supported Cooperative Work, 23(2), 205-221.

DeGuzman, G. V., \& Tang, A. I. (2011). Working in the Unoffice: A Guide to Coworking for Indie Workers, Small Businesses, and Nonprofits. Portland, Oregon: Night Owls Press LLC.

de Laart, M., \& Dawson, S. (2017). Is there Anybody out there? Place-based Networks for Learning. In L. Carvalho, Goodyear, \& M. de Laart (Eds.), Place-based Spaces for Networked Learning (pp. 100-110). New York: Routledge.

Department of Industry, Innovation \& Science. (n.d.-a). Industry Monitor - Innovation. Retrieved from https://industry.gov.au/Office-of-the-Chief-Economist/Publications/ IndustryMonitor2018/innovation/index.html

Department of Industry, Innovation \& Science. (n.d.-b). Innovation Map. Retrieved from https:// industry.gov.au/Office-of-the-Chief-Economist/Publications/AustralianIndustryReport/ innovation-map.html

Dourish, P. (2016). Algorithms and their others: Algorithmic culture in context. Big Data \& Society, 3(2), 1-11.

Dourish, P., \& Chalmers, M. (1994). Running out of space: Models of information navigation. In Proceedings of HCI '94, Glasgow, Scotland. New York: ACM Press.

Dunbar, K. (1997). How scientists think: On-line creativity and conceptual change in science. Washington, DC, USA: American Psychological Association.

Ellwood, A. (2012, August 22). The Dream Team: Hipster, Hacker, and Hustler. Retrieved from https://www.forbes.com/sites/andyellwood/2012/08/22/the-dream-team-hipster-hackerand-hustler/\#15e63bb92c85

Foertsch, C. (2011, January 13). The Coworker's Profile. Retrieved from http:// www.deskmag.com/en/the-coworkers-global-coworking-survey-168

Forlano, L. (2011). Building the Open Source City: Changing Work Environments for Collaboration and Innovation. In M. Foth, J. Donath, L. Forlano, M. Gibbs, \& C. Satchell (Eds.), From Social Butterfly to Engaged Citizen (pp. 437-460). Cambridge: MIT Press. 
Foth, M. (2015, December 2). Australia needs an innovation 'skunkworks.' The Conversation. Retrieved from https://theconversation.com/australia-needs-an-innovationskunkworks-51326

Foth, M., Forlano, L., \& Bilandzic, M. (2016). Mapping new work practices in the smart city. In H. Friese, G. Rebane, M. Nolden, \& M. Schreiter (Eds.), Handbuch Soziale Praktiken und Digitale Alltagswelten (pp. 1-13). Wiesbaden: Springer. doi: 10.1007/978-3-658-08460-8_33-1

Foth, M., Hughes, H. E., Dezuanni, M. L., \& Mallan, K. (2017, June 27). Skunkworks: Designing Regional Innovation Spaces for the Creative Fringe. In Workshop Proceedings of Designing Participation for the Digital Fringe, 8th International Conference on Communities and Technologies (C\&T), Troyes, France. Retrieved from https://eprints.qut.edu.au/107749/

Foth, M., Mitchell, P., \& Estrada-Grajales, C. (2018). Today's internet for tomorrow's cities: On algorithmic culture and urban imaginaries. In J. Hunsinger, L. Klastrup, \& M. Allen (Eds.), Second International Handbook of Internet Research. Springer. doi: 10.1007/978-94-024-1202-4_23-1

Freeman, J., \& Engel, J. S. (2007). Models of Innovation: Startups and Mature Corporations. California Management Review, 50(1), 94-119.

FYA. (2018). About Us. Retrieved from https://www.fya.org.au/about-us/

Gandini, A. (2015). The rise of coworking spaces:A literature review. Ephemera, 15, 193-205.

Garrett, L. E., Spreitzer, G. M., \& Bacevice, P. A. (2017). Co-constructing a Sense of Community at Work: The Emergence of Community in Coworking Spaces. Organization Studies, 38(6), 821-842.

Girard, B. (2009). The Google Way: How One Company Is Revolutionizing Management As We Know It. San Francisco: No Starch Press.

Gladwell, M. (2000). The tipping point. Boston: Little, Brown.

Golden, T. D., Veiga, J. F., \& Dino, R. N. (2008). The impact of professional isolation on teleworker job performance and turnover intentions: does time spent teleworking, interacting face-to-face, or having access to communication-enhancing technology matter? The Journal of Applied Psychology, 93(6), 1412-1421.

Granovetter, M. S. (1973). The Strength of Weak Ties. The American Journal of Sociology, 78(6), 1360-1380.

Gregg, M. (2011). Work's Intimacy. Cambridge: Polity Press.

Hauschildt, J., \& Salomo, S. (2011). Innovationsmanagement (Vol. 5). München: Vahlen.

He, L. (2013, March 29). Google's Secrets Of Innovation: Empowering Its Employees. Retrieved from https://www.forbes.com/sites/laurahe/2013/03/29/googles-secrets-ofinnovation-empowering-its-employees/\#d06671a57e7b

Houghton, K., Foth, M., \& Hearn, G. (2018). Working from the Other Office: Trialling Coworking Spaces for Public Servants. Australian Journal of Public Administration. doi: $10.1111 / 1467-8500.12317$

Hughes, M., Morgan, R. E., Ireland, R. D., \& Hughes, P. (2014). Social Capital and Learning Advantages: A Problem of Absorptive Capacity. Strategic Entrepreneurship Journal, 8(3), 214-233. 
Imre, H. (2007, Aug 28-31). Comparison of three methodological approaches of design research. In Proceedings International Conference on Engineering Design, ICED '07, Paris, France. Glasgow, UK: The Design Society.

Johnson, S. (2010). Where good ideas come from. New York: Riverhead Books.

Kojo, I., \& Nenonen, S. (2014). Evolution of co-working places: drivers and possibilities. Intelligent Buildings International, 9(3),1-12.

Koudelkova, P., \& Milichovsky, F. (2015). Successful innovation by motivation. Business: Theory and Practice, 16(3), 223-230.

Leadbeater, C. (2009). We-think: Mass innovation, not mass production (Vol. 2). London: Profile Books Ltd.

Liegl, M. (2014). Nomadicity and the Care of Place - on the Aesthetic and Affective Organization of Space in Freelance Creative Work. Computer Supported Cooperative Work, 23(2), 163-183.

Mejova, Y., Borge-Holthoefer, J., \& Weber, I. (2015). Bridges into the Unknown: Personalizing Connections to Little-known Countries. In Proceedings of the 33rd Annual ACM Conference on Human Factors in Computing Systems (CHI '15). New York, USA: ACM, 2633-2642. doi: 10.1145/2702123.2702152

Milgram, S. (1992). The familiar stranger: An aspect of urban anonymity. In J. Sabini \& M. Silver (Eds.), The Individual in a Social World: Essays and Experiments (pp. 68-71). New York: McGraw-Hill.

Monbiot, G. (2016). How did we get into this mess? London: Verso Books.

Moriset, B. (2013). Building new places of the creative economy. The rise of coworking spaces. Proceedings of the 2nd Geography of Innovation, International Conference 2014, Utrecht University, Utrecht (The Netherlands). Retrieved from https://halshs.archivesouvertes.fr/halshs-00914075

Norman, D. A. (2010). Technology First, Needs Last: The Research-Product Gulf. $A C M$ Interactions, $17(2), 38-42$.

O'Connor, G. C. (2006). Open, radical innovation: Toward and integrated model in large established firms. In H. W. Chesbrough, W. Vanhaverbeke, \& J. West (Eds.), Open Innovation (pp. 62-81). New York: Oxford University Press.

O'Connor, G. C., \& McDermott, C. M. (2004). The human side of radical innovation. Journal of Engineering and Technology Management, 21(1-2), 11-30.

Pariser, E. (2011). The Filter Bubble: How the New Personalized Web Is Changing What We Read and How We Think. New York: Penguin Publishing Group.

Paulos, E., \& Goodman, E. (2004). The familiar stranger: anxiety, comfort, and play in public places. In Proceedings of the SIGCHI Conference on Human Factors in Computing Systems (CHI '04) (pp. 223-230) New York, USA: ACM. doi: 10.1145/985692.985721

Piller, F. T. (2011). Open innovation with customers: Crowdsourcing and co-creation at threadless. In P. Sloane (Ed.), A Guide to Open Innovation and Crowdsourcing (pp. 110). London: Kogan-Page.

Polanyi, M. (1962). Personal knowledge: towards a post-critical philosophy (Vol. 2). London: Routledge.

Polanyi, M. (1966). The Creative Imagination. Chemical and Engineering News, 44(17), 85-93. 
Powell, W. W., \& Snellman, K. (2004). The Knowledge Economy. Annual Review of Sociology, 30(1), 199-220.

PTI. (2015, August 15). PM Narendra Modi announces 'Start up; Stand up India' initiative to create more jobs. Retrieved from http://indianexpress.com/article/india/india-others/pmnarendra-modi-announces-start-up-stand-up-india-initiative-to-create-more-jobs/

Roberts, E. B., \& Fusfeld, A. R. (1982). Critical functions: Needed roles in the innovation process. In R. Katz (Ed.), Career Issues in Human Resource Management (pp. 182207). Englewood Cliffs: Prentice Hall.

Rossitto, C., Bogdan, C., \& Severinson-Eklundh, K. (2014). Understanding Constellations of Technologies in Use in a Collaborative Nomadic Setting. Computer Supported Cooperative Work, 23(2), 137-161.

Rust, C. (2004). Design Enquiry: Tacit Knowledge and Invention in Science. Design Issues, 20(2), 76-85.

Sayiner, S. (2015). Physical Space Drives Innovation: How the Environment Can Increase an Organization's Productivity, Creativity, and Innovation. Intersect, 8(2), 1-18.

Spinuzzi, C. (2012). Working Alone Together: Coworking as Emergent Collaborative Activity. Journal of Business and Technical Communication, 26(4), 399-441.

Townsend, A., Forlano, L., \& Simeti, A. (2011). Breakout! Escape from the Office: Situating Knowledge Work in Sentient Public Spaces. In M. Shepard (Ed.), Sentient City: Ubiquitous Computing, Architecture, and the Future of Urban Space. Cambridge, Massachusetts: MIT Press.

Traitler, H., Coleman, B., \& Hofmann, K. (2015). Food industry design, technology and innovation. Hoboken: John Wiley \& Sons.

Valdez, A. C., Özdemir, D., Yazdi, M. A., Schaar, A. K., \& Ziefle, M. (2015). Orchestrating collaboration, using visual collaboration suggestion for steering of research clusters. Procedia Manufacturing, 3, 363-370.

Valdez, A. C., Schaar, A. K., Ziefle, M., \& Holzinger, A. (2014). Enhancing Interdisciplinary Cooperation by Social Platforms. In S. Yamamoto (Ed.), Human Interface and the Management of Information: Information and Knowledge Design and Evaluation (pp. 298-309). Cham: Springer International Publishing.

van Meel, J., \& Vos, P. (2001). Funky offices: Reflections on office design in the "new economy.' Journal of Corporate Real Estate, 3(4), 322-334.

Whittle, A., \& Mueller, F. (2009). 'I could be dead for two weeks and my boss would never know': telework and the politics of representation. New Technology, Work and Employment, 24(2), 131-143. doi: 10.1111/j.1468-005X.2009.00224.x

Wood, P., \& Landry, C. (2007). The Intercultural City: Planning for Diversity Advantage. London: Earthscan.

Yigitcanlar, T., \& Bulu, M. (Eds.). (2018). Urban Knowledge and Innovation Spaces: Insights, Inspirations and Inclinations form Global Practices. Abingdon, Oxon: Routledge.

Zuckerman, E. (2011). Desparately Seeking Serendipity. In Proceedings of the SIGCHI Conference on Human Factors in Computing Systems (CHI '11)., New York, USA: ACM. doi: $10.1145 / 1978942.2167183$ 